\title{
The Introduction of the Laryngeal Mask Airway for Surfactant Administration in Neonates with Respiratory Distress in Azerbaijan
}

\author{
Regina I. Nematova, MD ; Scott O. Guthrie, $\mathrm{MD}^{2}$ \\ 'Department of Anesthesiology and Intensive Care of Newborns, Scientific Research Institute of Pediatrics, Baku; \\ ${ }^{2}$ Division of Neonatology, Vanderbilt University School of Medicine, Nashville, TN, USA
}

In coordination with the the United States of America's Fulbright Program for Visiting Scholars, the Ministry of Health of the Republic of Azerbaijan invited a neonatologist from the Vanderbilt University School of Medicine (Nashville, TN, USA) to Baku to discuss the advanced care of and application of available technologies to care for critically ill and premature infants. One of the main focuses of this visit was to introduce a new method for the administration of pulmonary surfactant through the placement and use of the laryngeal mask airway. Training consisted of both theoretical and practical sessions held at the Shaki Perinatal Centre, Ganja Perinatal Centre, Azerbaijan Medical University, Scientific Research Institute of Pediatrics, Scientific Research Institute of Gynecology and Obstetrics, Republican (Central, National) Perinatal Centre and Republican (Central, National) Clinical Hospital. Nearly two hundred neonatal physicians were trained to use this device. The objective of this paper is to review Neonatal Respiratory Distress Syndrome and discuss treatment of this common neonatal problem with a laryngeal mask airway and the instillation of surfactant.

Keywords: acute poisoning, epidemiology, Azerbaijan

\section{Use of the Laryngeal Mask Airway for Surfactant Administration}

Respiratory Distress Syndrome (RDS) is caused by the deficiency of pulmonary surfactant in preterm neonates. The incidence of the disease increases with decreasing gestational age. Infants born less than 28 weeks have a $60 \%$ chance of developing RDS while those born between 28 and 34 weeks have a $30 \%$ chance. Late preterm infants born at 35 and 36 weeks are still at risk as $8 \%$ of these infants may be impacted. ${ }^{1}$ RDS remains a major problem in newborn infants worldwide and if left untreated, it leads to high mortality reported to be between 57 to $89 \%$ in low- and middleincome countries (LMICs). ${ }^{2}$ It is estimated that every year approximately 1.4 million neonates develop RDS and this will be fatal for many of them. $^{3}$

The introduction of pulmonary surfactant replacement in the 1980s for the treatment of RDS revolutionized the care of critically ill infants. Several randomized trials and meta-analyses have shown that intra-tracheal administration of animal derived surfactants reduces mortality and decreases the risk of air leak and bronchopulmonary dysplasia or death. ${ }^{4-8}$ While originally developed specifically for RDS, surfactant replacement therapy (SRT) has also been found to be beneficial in other newborn causes of respiratory distress more commonly seen in term infants such as congenital pneumonia and meconium aspiration syndrome. ${ }^{9,10}$

The standard method of surfactant delivery is to intubate the infant and then provide SRT by bolus instillation through the endotracheal tube. This is typically followed by mechanical ventilation. Due to the desire to avoid the complications of mechanical ventilation and the success of noninvasive respiratory support for premature infants the intubation, surfactant administration, and rapid extubation method (INSURE technique) to continuous positive airway pressure (CPAP) has been widely adopted. ${ }^{11}$

Intubation, necessary for intra-tracheal administration of surfactant, is an invasive procedure with risks which include esophageal perforation, right main bronchus intubation, clinical instability associated with accidental extubation, and/or tracheal tube obstruction. Transient adverse events such as hypoxemia, 
bradycardia, hypotension, and systemic and/or pulmonary hypertension are also frequently seen. These may occur in up to $39 \%$ of intubations. ${ }^{12-15}$ Attempts are often unsuccessful, with a first-time failure rate of up to $70 \% .{ }^{16}$ Multiple attempts at intubation and the resulting physiologic stress may also result in intraventricular hemorrhage which can lead to long-term neurodevelopmental consequences. ${ }^{17,18}$ Bronchopulmonary dysplasia also occurs more frequently in those requiring intubation as the use of mechanical ventilation and positive pressure breaths start an inflammatory cascade eventually leading to alveolar damage. ${ }^{19,20}$

In an effort to avoid these complications of intubation, minimally invasive surfactant administration techniques have been developed. The use of a thin intratracheal catheter has been used with success (LISA technique) and has been demonstrated to reduce the need for mechanical ventilation. $^{21}$ This, however, still subjects the neonate to airway manipulation since a laryngoscope is used to place the catheter. Aerosol delivery of surfactant is quite promising as it avoids any manipulation of the airway, but there is currently no approved device. This delivery method has been reported to take 1-2 hours for completion and requires that a larger volume of surfactant be used in comparison to tracheal instillation. $^{22}$

The laryngeal mask airway (LMA) is a well recognized and inexpensive device which can be used to resuscitate a neonate. ${ }^{23}$ Placement requires minimal technical skills in comparison to tracheal intubation. ${ }^{24}$ Positive pressure breaths can also be given through the device to effectively ventilate and oxygenate the infant. ${ }^{25}$ Multiple clinical trials have shown that the LMA can also be an effective delivery device for surfactant.26-29 Since this approach is minimally invasive, surfactant is typically given at a lower oxygen concentration. This approach improves outcome and has been shown to decrease the need for tracheal intubation and ventilation by nearly $60 \%$ in infants $28-31$ weeks and by $26 \%$ in all infants who received surfactant by LMA. ${ }^{29}$

Since administering surfactant through an LMA requires minimal instrumentation and equipment, this technique can be applied to environments ranging from high resource neonatal intensive care units to community hospitals that are capable of providing CPAP. This technique has significant potential to improve care in Central Asian countries like Azerbaijan. The Azerbaijan Ministry of Health has a robust program which supplies surfactant to the neonatal care centers throughout the country. Since CPAP is readily available in these locations, SRT through a LMA should significantly impact neonatal morbidity and mortality and decrease healthcare utilization such as transports. An educational program was implemented in Azerbaijan in October of 2018 to teach SRT through the LMA to test this hypothesis.

\section{Educational Program}

Neonatal care providers were provided with LMA Surfactant Administration kits (Photo 1). These kits included: a size 1 iGel LMA (Intersurgical Ltd.), a disposable end-tidal $\mathrm{CO}_{2}$ detector (Mercury Medical), a T-connector to attach to the syringe to facilitate administration, and an algorithm in Azerbaijani explaining the process (Figure 1).

Surfactant and syringe to administer was provided by the Azerbaijani Ministry of Health. All providers listened to a lecture discussing RDS, the benefits of SRT, and how to use the LMA. They then watched a video demonstrating the technique. Learners were finally given hands-on simulation training with a manakin to perfect what they had learned (Photo 2). Recommendations for use were also suggested (Table 1). There have already been reports of successful use of this technique to improve the care of preterm infants in Azerbaijan (Photo 3). 


\section{Discussion}

The administration of surfactant in the neonatal intensive care units of Azerbaijan has traditionally been carried out by either INSURE or LISA. Both techniques require endotracheal intubation and possibly sedation. Endotracheal intubation requires experience that is difficult to gain if the physician is far from the larger perinatal centres. Transportation of newborns with respiratory distress syndrome in the first 24 hours is not always possible and easy ways to administer surfactant are a welcome improvement to help our physicians provide care that can decrease neonatal deaths and complications related to prematurity in the early stages of the disease process.

Even if transportation does occur, due to a lack of surfactant these newborns are frequently admitted in an extremely critical conditions and may require prolonged mechanical ventilation. The ability to provide surfactant by using the laryngeal mask in Azerbaijan will make it possible to begin treatment in the regional centres and thus, further reduce the mortality and morbidity of the preterm infant in our country.

The placement of the laryngeal mask airway can be done without any signifiant specialized training or skill. This can provide a long term airway to assist a baby with breathing and can also provide a means to deliver a lifesaving medication like surfactant. The Ministry of Health of the Republic of Azerbaijan will continue to provide education throughout the country to teach this technique and to develop a local protocol to assist with the introduction of this new therapy.

Taking into consideration the high rates of premature birth and the associated morbidity and mortality in our country, we do consider it appropriate to introduce the laryngeal mask airway in neonatal institutions throughout the territory of the Republic of Azerbaijan. Our hope is to continue to closely monitor our outcomes and continue to see improvement in neonatal care throughout our country.
Financial source: Did not use financial resources.

Conflict of interest: None.

\section{REFERENCES}

1. National Center for Health Statistics. Period Linked Birth/Infant Death Data. 2013; Available at: www.marchofdimes.org/peristats. Accessed October 2, 2018.

2. Kumar A, Bhat BV. Epidemiology of respiratory distress of newborns. Indian J Pediatr. 1996 JanFeb;63(1):93-8.

3. Liu L, Oza S, Hogan D, Chu Y, Perin J, Zhu J, Lawn JE, Cousens S, Mathers C, Black RE. Global, regional, and national causes of under-5 mortality in 2000-15: an updated systematic analysis with implications for the Sustainable Development Goals. Lancet. 2016 Dec 17;388(10063):3027-3035. doi:10.1016/S0140-6736(16)31593-8.

4. Collaborative European Multicenter Study Group. Surfactant replacement therapy for severe neonatal respiratory distress syndrome: an international randomized clinical trial. Pediatrics 1988; 82:683-91.

5. Ardell S, Pfister RH, Soll R. Animal derived surfactant extract versus protein free synthetic surfactant for the prevention and treatment of respiratory distress syndrome. Cochrane Database Syst Rev 2015 Aug 24;8:CD000144.

6. Fetus and Newborn Committee, Canadian Paediatric Society. Recommendations for neonatal surfactant therapy. Paediatrics \& Child Health 2005; 02;10(2):109-16.

7. Horbar JD, Soll RF, Sutherland JM, Kotagal U, Philip AG, Kessler DL, et al. A multicenter, randomized, placebo-controlled trial of surfactant therapy for respiratory distress syndrome. N Engl J Med 1989; 320:959-65.

8. Seger N, Soll R. Animal derived surfactant extract for treatment of respiratory distress syndrome. Cochrane Database Syst Rev. 2009; (2):CD007836.

9. El Shahed AI, Dargaville PA, Ohlsson A, Soll R. Surfactant for meconium aspiration syndrome in term and late preterm infants. Cochrane Database Syst Rev. 2014 Dec 14;(12):CD002054. doi: 10.1002/14651858.CD002054.pub3.

10. Deshpande S, Suryawanshi P, Ahya K, Maheshwari R, Gupta S. Surfactant Therapy for Early Onset Pneumonia in Late Preterm and Term Neonates Needing Mechanical Ventilation. J Clin Diagn Res. 2017 Aug;11(8):SC09-SC12. doi:10.7860/JCDR/2017/28523.10520.

11. Polin RA, Carlo WA; Committee on Fetus and Newborn; American Academy of Pediatrics. Surfactant replacement therapy for preterm and term neonates with respiratory distress. Pediatrics. 2014 Jan;133(1):156-63. doi: 10.1542/peds.2013-3443.

12. Raju TN, Vidyasagar D, Torres C, Grundy D, Bennett 
EJ. Intracranial pressure during intubation and anesthesia in infants. J Pediatr 1980; 96:860-2.

13. Marshall TA, Deeder R, Pai S, Berkowitz GP, Austin TL. Physiologic changes associated with endotracheal intubation in preterm infants. Crit Care Med 1984; 12:501-3.

14. Friesen RH, Honda AT, Thieme RE. Changes in anterior fontanel pressure in preterm neonates during tracheal intubation. Anesth Analg 1987; 66:874-8.

15. O'Donnell CP, Kamlin CO, Davis PG, Morley CJ. Endotracheal intubation attempts during neonatal resuscitation: success rates, duration, and adverse effects. Pediatrics 2006; 117:e16-21.

16. Lane B, Finer N, Rich W. Duration of intubation attempts during neonatal resuscitation. J Pediatr 2004; 145:67-70.

17. Sauer CW, Kong JY, Vaucher YE, Finer NN, Proudfoot JA, Boutin MA, Leone TA. Intubation attempts increase the risk for severe intraventricular hemorrhage in preterm infants: a retrospective cohort study. J Pediatr 2016; 177:108-13.

18. Wallenstein MB, Birnie KL, Arain YH, Yang W, Yamada NK, Huffman LC, et al. Failed endotracheal intubation and adverse outcomes among extremely low birth weight infants. J Perinatol 2016; 36:112-5.

19. Bjorklund LJ, Ingimarsson J, Curstedt T, John J, Robertson B, Werner O, Vilstrup CT. Manual ventilation with a few large breaths at birth compromises the therapeutic effect of subsequent surfactant replacement in immature lambs. Pediatr Res 1997; 42:348-55.

20. Van Marter LJ, Allred EN, Pagano M, Sanocka U, Parad R, Moore M, et al. Do clinical markers of barotrauma and oxygen toxicity explain interhospital variation in rates of chronic lung disease? The Neonatology Committee for the Developmental Network. Pediatrics 2000; 105:1194-201.

21. Lau CSM, Chamberlain RS, Sun S. Less Invasive Surfactant Administration Reduces the Need for Mechanical Ventilation in Preterm Infants: A MetaAnalysis. Glob Pediatr Health. 2017 Mar 24;4:2333794X17696683. doi:10.1177/2333794X17696683.

22. Minocchieri S, Berry CA, Pillow JJ; CureNeb Study Team. Nebulised surfactant to reduce severity of respiratory distress: a blinded, parallel, randomised controlled trial. Arch Dis Child Fetal Neonatal Ed. 2018 Jul 26. pii: fetalneonatal-2018-315051. doi: 10.1136/archdischild-2018-315051.

23. Weiner GM, Zaichkin J. Textbook of Neonatal Resuscitation (NRP), 7th Ed. American Academy of Pediatrics. 2016.

24. Pejovic NJ, Trevisanuto D, Nankunda J, Tylleskär T. Pilot manikin study showed that a supraglottic airway device improved simulated neonatal ventilation in a low-resource setting. Acta Paediatr. 2016 Dec;105(12):1440-1443. doi: 10.1111/apa.13565.

25. Tracy MB, Priyadarshi A, Goel D, Lowe K, Huvanandana J, Hinder M. How do different brands of size 1 laryngeal mask airway compare with face mask ventilation in a dedicated laryngeal mask airway teaching manikin? Arch Dis Child Fetal Neonatal Ed. 2018 May;103(3):F271-F276. doi: 10.1136/archdischild-2017-312766.

26. Trevisanuto D, Grazzina N, Ferrarese P, Micaglio M, Verghese C, Zanardo V. Laryngeal mask airway used as a delivery conduit for the administration of surfactant to preterm infants with respiratory distress syndrome. Biol Neonate. 2005;87(4):217-20.

27. Pinheiro JMB, Santana- Rivas Q, Pezzano C. Randomized trial of laryngeal mask airway versus endotracheal intubation for surfactant delivery. J Perinatol 2016; 36: 196-201.

28. Barbosa RF, Simoes e Silva AC, Silva YP. A randomized controlled trial of the laryngeal mask airway for surfactant administration in neonates. J Pediatr 2017; 93:343-350.

29. Roberts KD, Brown R, Lampland AL, Leone TA, Rudser KD, Finer NN, et al. 2018. Laryngeal mask airway for surfactant administration in neonates: a randomized, controlled trial. J Pediatr 193: 40-46.e1. 